\title{
Content Management for the Virtual Library
}

Traditional, larger libraries can rely on their physical collection, coffee shops, and study rooms as ways to entice patrons into their library. Yet virtual libraries merely have their online presence to attract students to resources. This can only be achieved by providing a fully functional site that is well designed and organized, allowing patrons to navigate and locate information easily. One such technology significantly improving the overall usefulness of Web sites is a content management system (CMS). Although the CMS is not a novel technology per se, it is a technology smaller libraries cannot afford to ignore. In the fall of 2004, the Northcentral University Electronic Learning Resources Center (ELRC), a small, virtual library, moved from a static to a database-driven Web site. This article explains the importance of a CMS for the virtual or smaller library and describes the methodology used by ELRC to complete the project.

\section{State of the virtual library}

The Northcentral University Electronic Learning Resource Center (ELRC), a virtual library, recently moved from a static to a databasedriven Web site in 2004. ${ }^{1}$ Before this, the site consisted of 450 static pages and continued to multiply due to the creation and expansion of Northcentral University (NCU) programs. To provide the type of service demanded by our Internet-savvy patrons, the ELRC felt it needed to evolve to the next stage of Web management and design.

NCU, with a current enrollment of roughly twenty-one hundred fulltime students, is one of many forprofit virtual universities (including the University of Phoenix, Capella, and Walden, among others) seeking to carve a niche in the education mar-

Ed Salazar (esalazar@ncu.edu) is Reference/Web Librarian at Northcentral University. ket by offering professional degrees entirely online. ${ }^{2}$ In the past few years, distance education has experienced exponential growth, causing virtual universities to flourish, but forcing on their libraries the challenge of keeping pace. $^{3}$ Typically, virtual libraries are manned by a limited staff comprised of one or two librarians who are responsible for all facets of the library, including interlibrary loan, virtual reference, library instruction, and Web site management, among other library duties. ${ }^{4}$ Web site management, as expected, becomes cumbersome when a site exceeds two hundred or more static pages and a clear and structured system is not in place to maintain a proliferating number of Web pages.

Because virtual, for-profit libraries do not rely on public funding and taxes, they tend not to be as concerned about autonomy as public or state libraries, which must find ways to stay within budget and curtail expenses. On the same note, some academic libraries prefer to maintain a local area network (LAN), while other libraries may not have the staff, resources, or need for such a system. Thus, for some virtual libraries, such as ELRC, the incorporation of technology takes on a more dependent role. That is, where some libraries are encouraged to explore open source applications and create homegrown tools, the virtual, smaller-staffed library finds itself more or less reliant on its university's information technology (IT) department. ${ }^{5}$

Virtual libraries address the needs of distance education students, who demand an equivalent, if not surpassing, level of service and instruction as they would expect to find at physical libraries. ${ }^{6}$ Meeting these needs requires a great deal of creativity, ingenuity, and a strong technical background. Recent trends in developing technologies such as MyLibrary, learning objects, blogs, virtual chat, and federated searching have broadened the scope of possibilities for the smaller-staffed, virtual library. In particular, a content management system (CMS) utilizes a combination of tools that provide numerous advantages, as outlined below:

1. The creation of templates that maintain a consistent design throughout the site

2. The convenience of adding, updating, and deleting information from a single, online location

3. The creation and maintenance of interactive pages or learning objects

4. The implementation of a simple editing interface that eliminates knowledge of extensible hypertext markup language/hypertext markup language (XHTML/ HTML) by library staff

Simply defined, a CMS is comprised of a database, server pages such as Active Server Page (ASP), Personal Home Page (PHP), or ColdFusion; a Web server-for example, Internet Information Server (IIS), Personal Web Server (PWS), or Apache; and an editing tool to manage Web content. ${ }^{7}$ These resources vary in price, but for a virtual library integrated into a larger university, it is ideal to implement applications and software supported by the university. For the autonomous academic library, this may differ. There are advantages and disadvantages for using proprietary and nonproprietary software, and it is left to the library, virtual or physical, to determine the type of resources needed to meet the goals and mission of the university. ${ }^{8}$ Although the scope of this article focuses on the creation of tools for a homegrown CMS, some libraries may wish to explore commercial CMS packages that include additional services such as technical support. These CMS packages will vary in price and services depending on the vendor and the needs of the library. ${ }^{9}$

\section{ELRC transformed}

In fall 2004, a group that consisted 
of two librarians, the education chair, and programmer, convened to discuss the redesign of the ELRC Web site, which had become increasingly difficult to manage. Specifically, the amount of duplicated content, inconsistent design and layout, and unstructured architecture of the site posed severe navigational and organizational problems. The group selected and compared other academic library sites to determine a desired design and theme for the new ELRC site. Discussions also involved the addition of features such as a site search and breadcrumbs, which the group felt were essential. As a result, the creation of a homegrown CMS using proprietary software became the route of choice to meeting the increasing demands of patrons and the need to expand the site.

Because NCU utilizes Microsoft (MS) information system products, it was agreed MS or MS-compatible applications would be used to create the CMS, which consisted of SQL Server, IIS, ASP, Visual Basic Script (VBScript), Jspell Iframe, and MS Visual Interdev. MS Visual Interdev and Jspell Iframe supplanted our previous Web editor, MS FrontPage, which seemed to generate superfluous code and thus made it difficult to debug or alter the design and layout of pages. Also, using Jspell Iframe eliminated the need for future NCU librarians to possess an expertise in XHTML/HTML. With these pieces in place, the arduous task of culling content from static pages and entering it into a database was begun.

\section{The database}

The SQL Server database helped in organizing and structuring content, and allowed for the creation of templates and administration (admin) pages. ${ }^{10}$ In addition, the database played an integral part in creating the search, breadcrumb, and site map features the group so desperately wanted. A significant amount of time was spent weeding the site for information that had become obsolete or irrelevant to ELRC. It should be noted that the group originally attempted to use Access for a database but stumbled across several problems, one being the inability to maintain a stable and reliable connection to the database.

\section{The templates}

With the database nearly complete, the programmer began creating ASP templates in MS Visual Interdev. These templates basically serve as the shell of the Web page, preserving the design and layout elements of the page while extracting unique content based on a user's request. In essence, a single template can produce hundreds of pages consistent in design. Likewise, a single change to the template can alter the entire design of the site. For the ELRC, seven templates were created for more than 450 pages. Figure 1 shows the ELRC course guides template. Figure 2 shows the public view of the ELRC course guide template.

Changes to the templates are done using MS Visual Interdev, which offers a user-friendly environment for managing Web pages. MS Visual Interdev also includes helpful features, such as highlighting code errors for easy debugging, and the ability to access, create, and maintain stable connections to databases. ${ }^{11}$ In addition, the MS Visual Interdev editor recognizes commonly used ASP commands, allowing the user to save time by utilizing keyboard shortcuts when programming.

Besides creating templates, ASP server-include files and cascading style sheets (CSS) were incorporated, allowing for the easy modification of code on a single file instead of each and every page or template. This, in particular, is time-efficient when having to add or change database connections or design elements. Also, the ELRC took extra precaution to ensure that style elements met the accessibility requirements and standards set forth by the World Wide Web Consortium (W3C), as well as tested the site on other browsers, such as Firefox and Netscape. ${ }^{12}$

As the site continues to grow and expand, so may the need for additional templates. Creation or replication of templates is simple, requiring a basic understanding of programming and the re-assigning of new variables in the code to match added or modified tables. There is some speculation in the near future of migrating the site to the ASP.NET environment for added functionality and security. If and when that time comes, the ELRC will be ready. At present, NCU is not considering the use of open source code or applications (the exception being the Apache Web server); this is primarily due to available technical support, security, and intuitiveness of use associated with commercial software. In addition, the NCU information system was built using commercial software and a complete transition to open source, at the moment, is not possible or desirable.

With the templates complete, the ELRC began running a prototype of the new site, making it accessible to students and faculty from a link on the old site. A survey was created that allowed users to comment on the new site. One detail of importance to note is that the survey duplicated a prior survey done on the old site in 2003 in order to provide the ELRC with comparative data.

\section{The admin pages}

The next phase of the project required the creation of admin pages, which would allow content to be quickly added, updated, and deleted on the site. These pages, like the templates, were created in MS Visual Interdev; display content is housed within the database on the Web, thus allowing 
it to be changed on the fly. Figure 3 shows all of the Web pages for the ELRC within a table.

What is particularly convenient about the admin edit pages is the incorporation of the Jspell Iframe editor, which serves as the frontend editor to the site. The reason for using Jspell Iframe, as stated earlier, is its ease of use: the simple tool bar provides the basic, essential tools necessary for creating content without the daunting number of buttons and menu selections other editors tend to have. Also, Jspell Iframe is reasonably priced and does not entail a complex installation or require any space on local hard drives; instead, the program is maintained on the server. Consequentially, all that is required is the insertion of the Jspell Iframe JavaScript code into the Web pages.

In addition to Jspell Iframe, fields within admin edit pages are or can be pre-populated by content in the database. For instance, the title or display order of links can be easily edited or changed. Longer text fields comprised of paragraphs are created or modified using Jspell Iframe. Deleting a page is simple, requiring only the click of a delete button on the bottom, righthand corner. Figure 4 shows Jspell Iframe embedded within an admin edit page.

The admin add page is straightforward. Information is entered into the fields appearing on a form page, and the proper page type designation is selected from a drop-down menu. Yet, more importantly, the admin add and the admin edit pages can filter information to specific users for security purposes and library needs. Figure 5 shows an admin add page. Figure 6 shows an admin edit page.

The admin pages were designed with flexibility in mind. Main column headings may be sorted, as seen in figure 3, allowing one to locate a particular page. The sorting feature also displays the inner structure of the database that, in turn, identifies parent-child relationships between pages in the ELRC, which is useful and necessary when adding pages to the ELRC site.

Due to the careful thought used in creating the admin pages, they have proven to be extremely effective and useful in maintaining a library Web site. Each and every change to the site can be made on the Web, allowing content to be edited remotely and

eliminating the need for installing and maintaining expensive editing software on local and remote machines.

\section{Usability testing}

With the site completed, the ELRC felt it important to perform usability

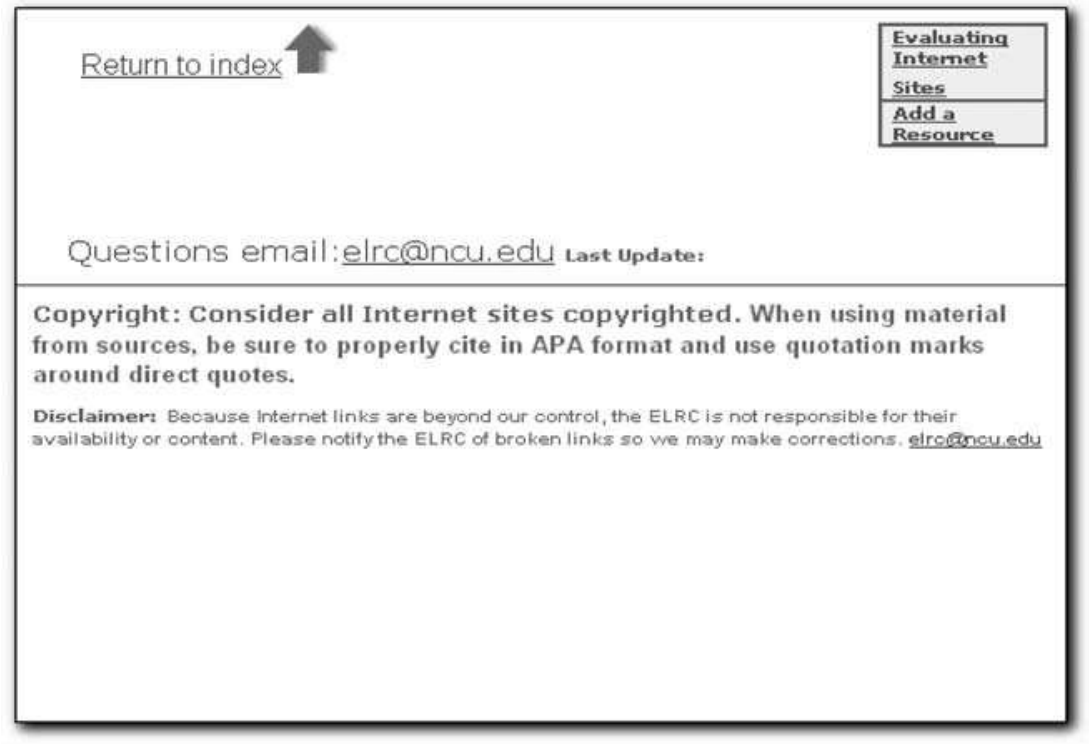

Figure 1. ELRC course guide template

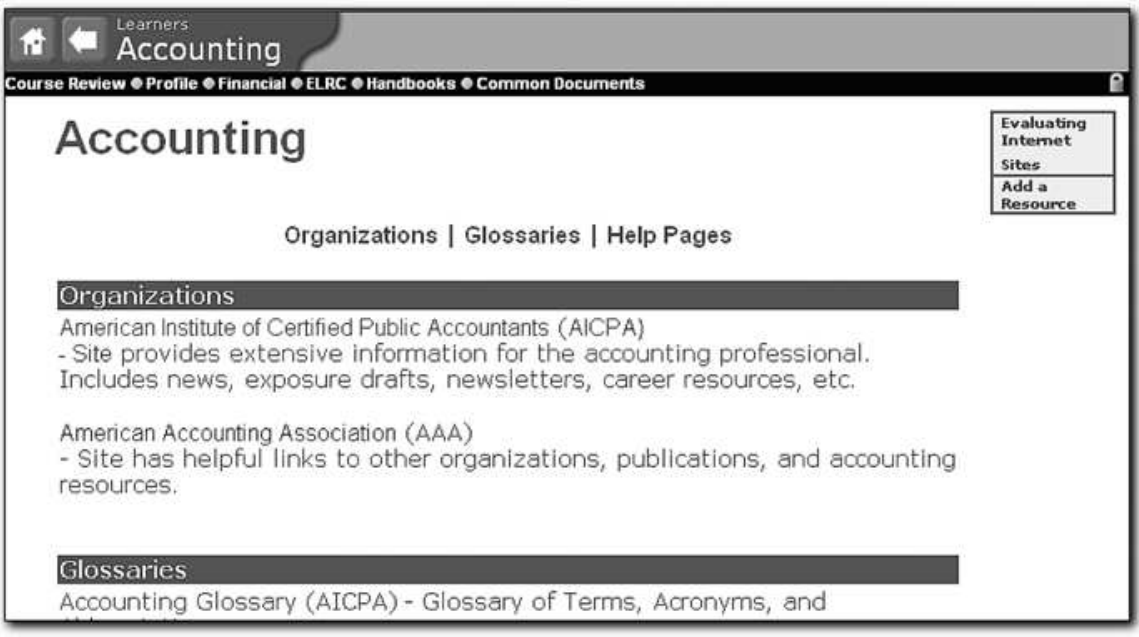

Figure 2. Public view of the ELRC course guide template 
tests, but how does a virtual library conduct usability testing when all of its students are distance education students? This is a difficult question that involves some ingenuity to answer. In order to solve this problem, staff members were propositioned (begged) to volunteer for the study. Total staff acquired was five. Also, a local college class of about ten students was persuaded to participate in the study.
Granted, the total number of subjects is not representative of the NCU student body; however, substantial changes to the site were made from the data gathered. More usability testing is expected in the immediate future.

\section{The findings}

Usability testing complete, the site was

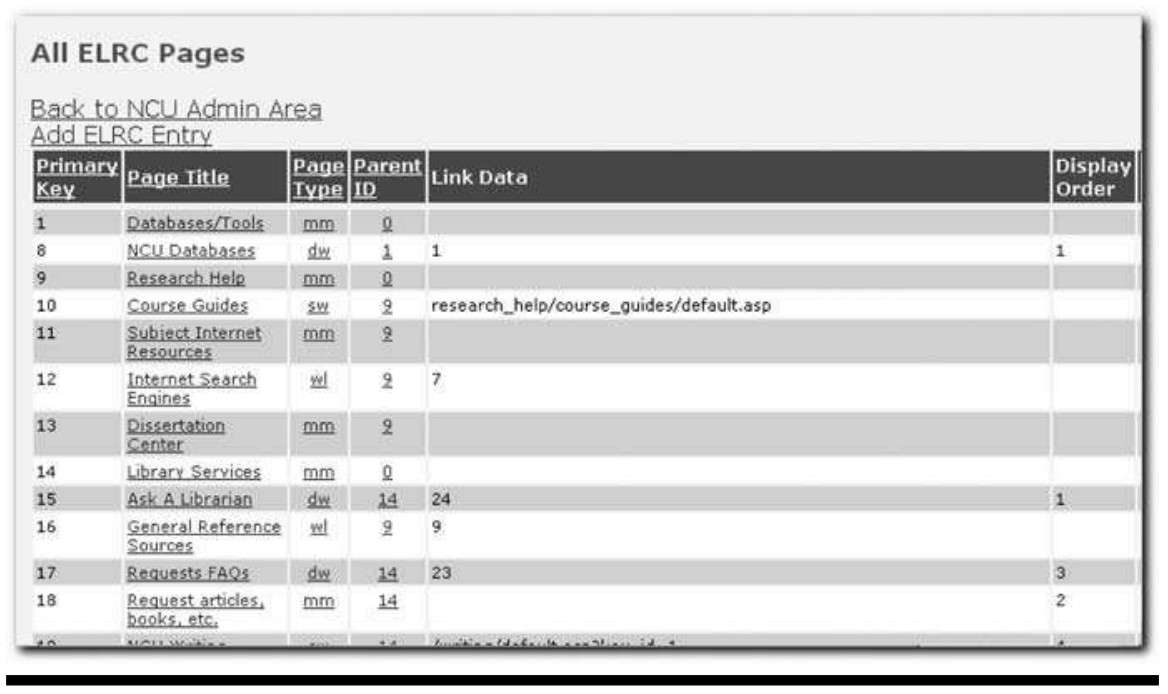

Figure 3. Web pages for ELRC within a table

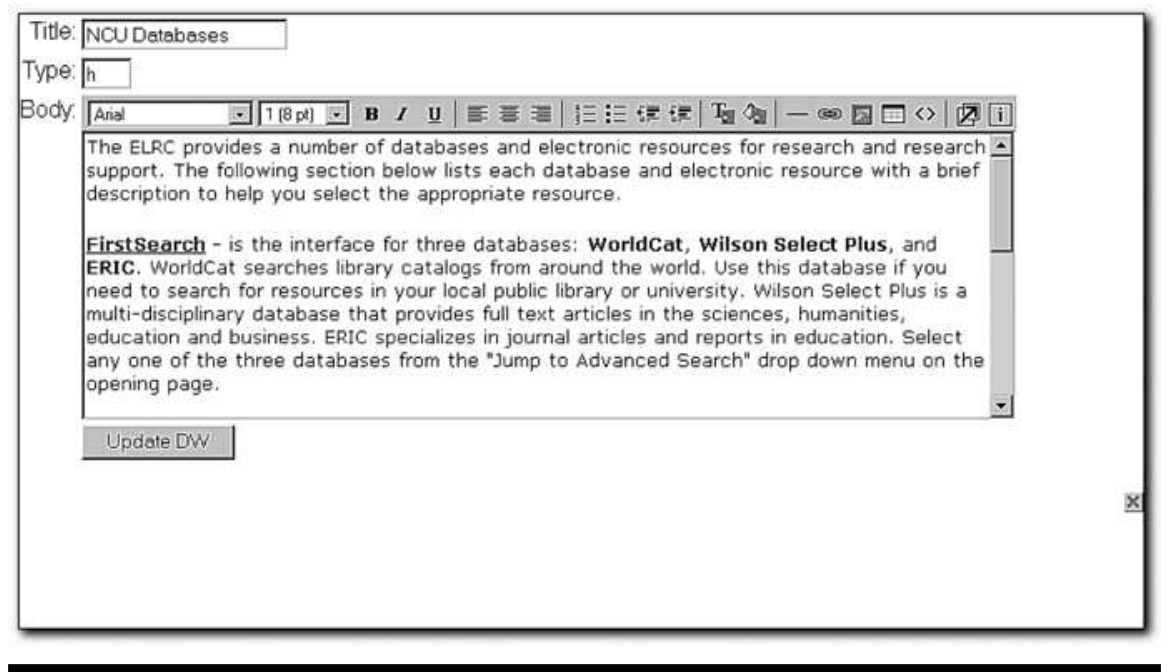

Figure 4. Jspell Iframe editor embedded within an admin edit page

launched. During this period, a few minor hang-ups were experienced, including broken links, form page errors, and stray design elements, but these were only minor problems that were quickly fixed. Feedback from the ELRC survey showed that nearly all of the students and faculty, roughly fifty respondents, approved of the changes by commenting that the site had improved in layout and organization of content as well as navigation. Also, responses and comments from usability testing participants were equally positive and encouraging. Figure 7 shows the new NCU Learners ELRC home page.

Although it is difficult to establish a direct connection between the ELRC site and usage, recent statistics appear promising. Since the inception of the new site in December 2004, the number of visits to the ELRC Learners home page has jumped 10 percent. This number is expected to rise as NCU continues to grow and students become more acquainted and familiar with the site.

The project took nearly six months to complete and required the expertise of a programmer. Although programming may be outside the requisites of a distance librarian, managing the site is not. A general understanding of control statements and SQL is all that is needed. For the distance librarian who spends almost all of his or her time online, these skills can be acquired on the job or by taking introductory programming courses at a local college.

In the hope that the site will continue to expand in concert with the growing body of NCU students, recently the ELRC added a writing center and blog. With the entire site now being database driven, adding, updating, deleting content is done effortlessly. Ideally, students and faculty will play a greater role in the development of the ELRC site as a result of the changes. Involving patrons with the site can play an integral, beneficial role in their academic pursuits. 


\section{Conclusion}

The ELRC at NCU encourages other virtual or smaller libraries to explore their resources for improving their library Web sites, which involves understanding campus resources and personnel. With the ever-burgeoning growth of technological resources, every library—small or large, virtual or physical, public or private-can empower itself to meet the needs of Internet-savvy students. It is only a matter of being aware of the resources and putting them to good use.

\section{References and notes}

1. The NCU ELRC Web site is comprised of three separate sites: the Public site www.ncu.edu/elrc (accessed Dec. 2, 2004), the Mentors site http://mentors .ncu.edu/elrc (accessed Dec. 2, 2004), and the Learners site http:/ / learners.ncu .edu/elrc (accessed Dec. 2, 2004). Although similar in design, each site is tailored to meet the needs of each individual group as well as protect NCU's resources, services, and information. Access to subscription resources and personal information is available upon authentication of the user to the site.

2. For a detailed overview of virtual libraries, see Valerie A. Akuna, "Virtual Universities: The New Higher Education Paradigm," Estrella Mountain College, http://students.estrellamountain .edu/drakuna/VirtualUniversities.htm (accessed Feb. 15, 2005).

3. U.S. Department of Education, National Center for Education Statistics, "The Condition of Education 2004," Distance Education at Postsecondary Institutions, http://nces.ed.gov/pubsearch/ pubsinfo.asp?pubid=2004077 (accessed Feb. 8, 2005).

4. For more information on the role of the virtual librarian in a virtual university, see Jan Zastrow, "Going the Distance: Academic Librarians in the Virtual University," University of Hawaii-Kapiolani Community College, http://library.kcc .hawaii.edu/ illdoc/DE/DEpaper.htm (accessed Jan. 29, 2005).
5. For an overview on developing an Open Source CMS, please see Mark Dahl, "Content Management Strategy for a College Library Web Site," Information Technology and Libraries 23, no. 1 (2004).

6. For a detailed discussion on distance education and virtual libraries, see Smiti Gandhi, "Academic Librarians and Distance Education: Challenges and Opportunities," Reference \& User Services Quarterly 43, no. 2 (2003).
7. For detailed information on using ASP pages for managing databases, see Xiaodong Li and John Paul Fullerton, "Create, Edit, and Manage Web Database Content Using Active Server Pages," Library Hi Tech 20, no. 3 (2002); see also, Bryan H. Davidson, "Database Driven, Dynamic Content Delivery: Providing and Managing Access to Online Resources Using Microsoft Access and Active Server Pages," OCLC Systems and Services 17, no. 1 (2001).

\section{Add New ELRC Page}

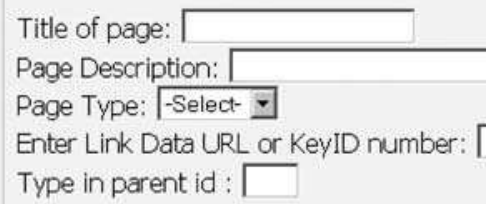

Figure 5. Admin add page

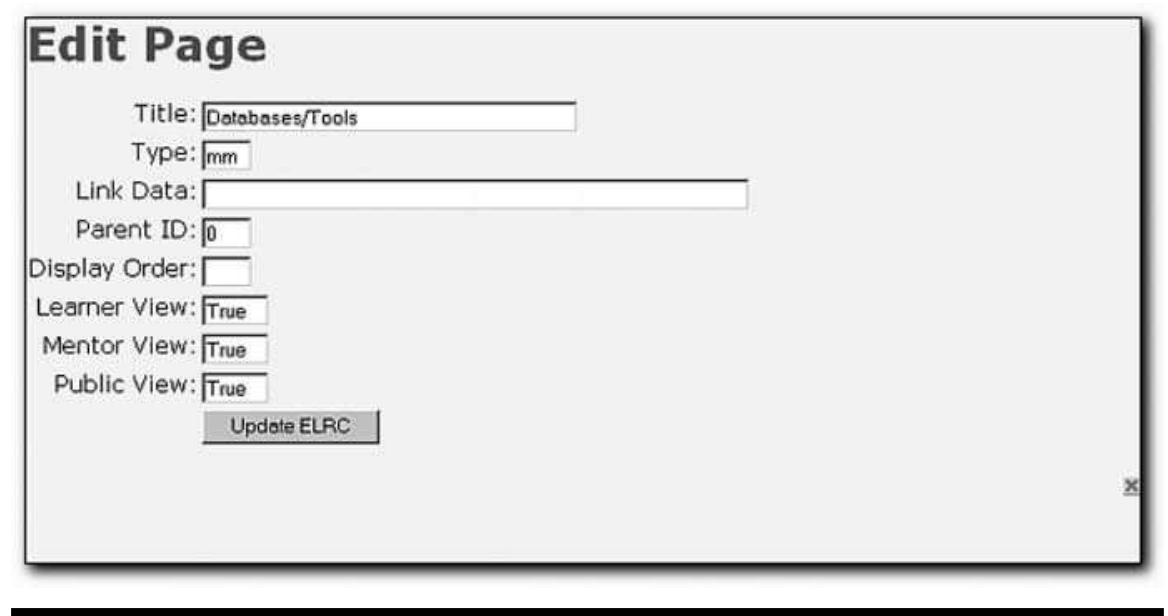

Figure 6. Admin edit page 
8. For advantages and disadvantages of open source and proprietary software, see John Caroll, "Open Source versus Proprietary: Both Have Advantages," Special to CNET Asia, http://asia.cnet.com/ builder/program/work/0,39009380,3918 1451,00.htm (accessed Feb. 4, 2004); see also, Stephen Shankland, "Study: OpenSource Database Going Mainstream," CNET, http://ecoustics-cnet.com.com/

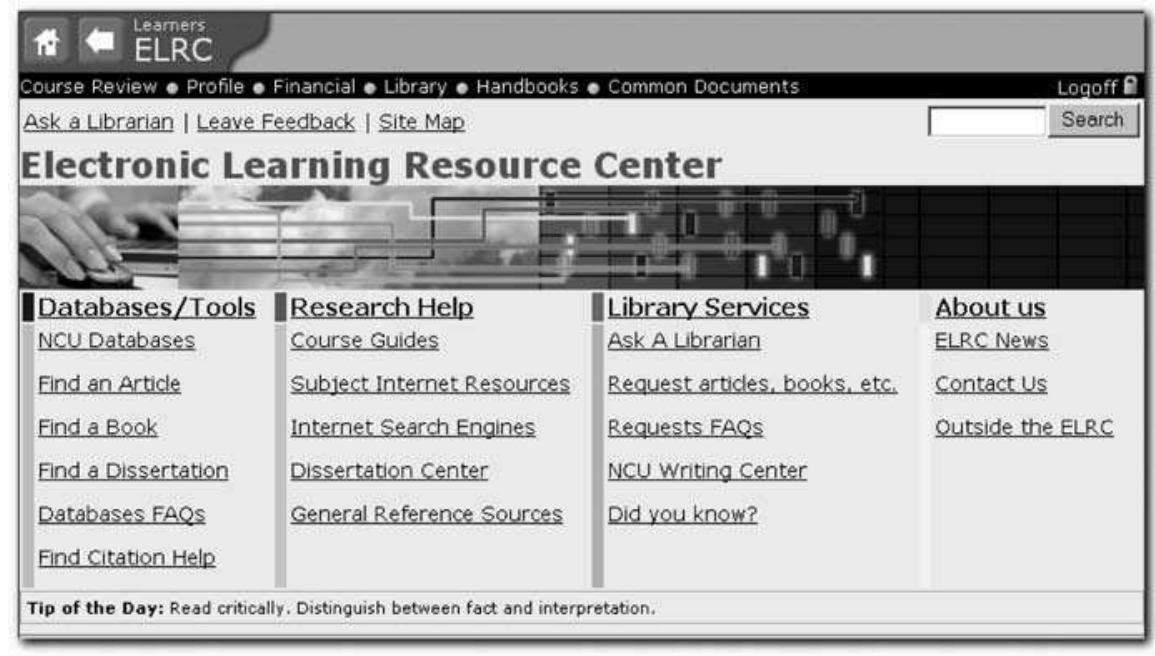

Figure 7. ELRC Learners home page
Study+Open-source+databases+going +mainstream/2100-7344_3-5171543.html (accessed Feb. 4, 2004).

9. For information on commercial content management vendors and prices, see CMS Watch, www.cmswatch.com/CMS/ Vendors (accessed Feb. 15, 2005). "SQL Server 2000 Product Overview," Microsoft Windows Server System, www.microsoft. $\mathrm{com} / \mathrm{sql} /$ evaluation/overview/default. asp (accessed Feb. 15, 2005).

10. For a review on Visual Interdev, see Maggie Biggs, "Visual Studio 6.0 Demonstrates Improved Integration," InfoWorld 20, no. 35 (1998), www.infoworld.com/ cgi-bin/displayTC.p1?/reviews/980831 vstudio6.htm (accessed Feb. 4, 2004).

11. "Checklist of Checkpoints for Web Content Accessibility Guidelines 1.0," W3C, www.w3.org/TR/WAI-WEBCON TENT/full-checklist.html (accessed Feb. 1, 2005).

12. Jspell Iframe 2004, www.jspell .com/iframe-spell-checker.html (accessed Dec. 2, 2004).

\section{Index to Advertisers}

EBSCO

LAMA cover 2

cover 3
LITA

cover 4 